\title{
Review Article \\ Why Did an Out-of-Hospital Shift of Death and Dying Occur in Canada after 1994?
}

\author{
Donna M. Wilson, ${ }^{1}$ Jessica A. Hewitt, ${ }^{2}$ Roger E. Thomas, ${ }^{3}$ and Boris Woytowich ${ }^{1}$ \\ ${ }^{1}$ Faculty of Nursing, University of Alberta, Edmonton, AB, Canada T6G 2C9 \\ ${ }^{2}$ Faculty of Rehabilitation Medicine, University of Alberta, Edmonton, AB, Canada T6G 2G4 \\ ${ }^{3}$ Family Medicine, University of Calgary, Calgary, AB, Canada T2N 4N1 \\ Correspondence should be addressed to Donna M. Wilson; donna.wilson@ualberta.ca
}

Received 28 June 2013; Accepted 11 November 2013; Published 2 February 2014

Academic Editors: L. Deliens and R. Viola

Copyright (C) 2014 Donna M. Wilson et al. This is an open access article distributed under the Creative Commons Attribution License, which permits unrestricted use, distribution, and reproduction in any medium, provided the original work is properly cited.

Canadian population mortality data reveal a significantly reduced proportion of deaths occurring in hospitals after 1994. Hospital deaths peaked at $80.5 \%$ in 1994, after a longstanding hospitalization-of-death trend in Canada. A decline in hospital-based death and dying has also occurred in some other countries. As the place of death can have multiple significant direct and indirect impacts on dying individuals, their families, and health services utilization and costs, it is important to understand factors for an out-of-hospital shift. An integrative review of Canadian print literature from 1995 was undertaken to identify these factors, with three themes emerging: (1) changes in health care and health system reforms after 1994 reduced both the availability and desirability of hospitalbased care, (2) sociodemographic developments including aging of the population, increased multiculturalism, and diversity in accepted end-of-life care practices shifted place preferences, and (3) advances in palliative and end-of-life care, including a palliative care expansion out of hospital, supported nonhospital death, and dying processes. The period following 1994 was thus a time of major transformation during which the place of death and dying underwent important changes that supported and promoted a transition from hospital-based end-of-life care.

\section{Introduction}

The 1966 Medical Care Act and 1984 Canada Health Act are widely credited for shaping Canada's health system into a publicly funded universal system designed so that all Canadian citizens have access to medically necessary health care services. However, this system has been extensively oriented to hospital-based care, in part because no hospital user fees are allowed. Terminally ill people can be high users of hospitals as they often have significant health problems, and their symptoms and the overall burden of illness typically increase as death approaches $[1,2]$. Not surprisingly, an increase in hospital-based death and dying occurred over much of the twentieth century in Canada as hospitals grew both in number and size, and also as their ability to successfully treat illnesses increased [2,3]. However, 1994-2004 Canadian population mortality data demonstrate a substantial shift after 1994 of location of death and thus also dying and end-of-life care out of hospital; in 2004 just over $60 \%$ of all deaths in Canada were recorded as having taken place in hospital as compared to $80.5 \%$ in $1994[3,4]$. More recent mortality data reveal a rate of $66 \%$ [5]. The place where death and dying occurs can have multiple significant direct and indirect impacts on dying individuals, their families and health services utilization and costs, and so it is important to understand the influences or factors for this unexpected out-of-hospital shift. The identification of factors related to this out-of-hospital shift could be helpful for health services planning in Canada and other countries where this same outof-hospital shift is desired or already occurring $[1,6,7]$.

\section{Materials and Methods}

An integrative literature review was undertaken to understand why the out-of-hospital shift of death and thus also dying and end-stage end-of-life care occurred in Canada 
after 1994. This is an appropriate method for data collection because to rely only on purely numerical databases would not provide a definitive and comprehensive answer. An alternative strategy would be to interview health care or other experts but their opinions are unlikely to identify all factors initiating and continuing this shift out of hospital. A previous literature review was successful at identifying many diverse influences for the hospitalization of death and dying in Canada until 1994 [2].

Integrative and systematic literature reviews are designed to carefully search for print information on specific questions and then examine the collected body of information to determine what evidence exists and if information gaps are present. In contrast to Cochrane-style systematic reviews that focus on randomized control trials and experimental research reports and other systematic reviews which similarly employ an exhaustive search for research literature and then an exclusion of a substantial proportion of articles because of methodological quality and other issues, integrative reviews involve gathering a wider range of print information and retaining both peer-review and nonpeer-review articles because the focus of inquiry is on complex events and multifactorial processes [8]. Our search was conducted using a wide range of Canadian English-language print information to identify factors or influences contributing to the shift of death and dying out of Canadian hospitals after 1994. Indexes of many Canadian scholarly print and online journals which are not restricted to association members, one key longstanding national magazine, and a Canadian-based palliative care journal 1995-2012 were first searched (Table 1). These sources contain research investigation reports, book reviews, nonresearch and expert opinion reports, and additional written works about timely and important topics of interest or concern to Canadian authors, journal/magazine editors, reviewers, and readers. These documents were therefore expected to reveal key factors of influences for the shift of death and dying out of hospital.

As the indexes were reviewed, articles were flagged that possibly indicated an event, development, or process that could have a direct or potential impact on the location of death, and/or on terminally ill or dying individuals, their families and/or other informal or formal caregivers, hospitals, and/or the health system as a whole. More specifically, any event, development, or process including social or societal, health care, health system, and palliative care that could potentially impact end-of-life care, dying and the location of death, or location of end-of-life care were sought. Flagged articles had their abstract read and then (if still deemed to be relevant) full-text articles were read to determine potential relevance. The authors of the retained articles (if a Canadian address for them was provided) and the references listed in the retained articles were also reviewed to identify additional articles that could more directly or clearly exemplify the identified factor or influence. During this search, influences or factors that would impact only a few people or only one region of Canada were not selected as the shift out of hospital was pan-Canadian.

Research ethics approval was not required for this project. A list of Canadian journals and other Canadian information
TABLE 1: Primary Canadian print information sources.

\begin{tabular}{|c|c|}
\hline Canadian scholarly journals & $\begin{array}{l}\text { Additional Canadian print } \\
\text { sources }\end{array}$ \\
\hline Canadian Bar Review & $\begin{array}{l}\text { Canadian Information for } \\
\text { Health Information (CIHI) }\end{array}$ \\
\hline Canadian Gerontological Collection & Federal Government \\
\hline Canadian Issues & Health Canada \\
\hline $\begin{array}{l}\text { Canadian Journal of Administrative } \\
\text { Sciences }\end{array}$ & $\begin{array}{l}\text { Health } \\
\text { Ministries/Departments in } \\
\text { Canada }\end{array}$ \\
\hline Canadian Journal on Aging & Journal of Palliative Care \\
\hline $\begin{array}{l}\text { Canadian Journal of Behavioural } \\
\text { Science }\end{array}$ & McLean's Magazine \\
\hline Canadian Journal of Economics & $\begin{array}{l}\text { Public Health Agency of } \\
\text { Canada }\end{array}$ \\
\hline $\begin{array}{l}\text { Canadian Journal of Experimental } \\
\text { Psychology B }\end{array}$ & Statistics Canada \\
\hline Canadian Journal of Geriatrics & \\
\hline $\begin{array}{l}\text { Canadian Journal of Infectious } \\
\text { Diseases }\end{array}$ & \\
\hline Canadian Journal of Law and Society & \\
\hline $\begin{array}{l}\text { Canadian Journal of Nursing } \\
\text { Administration }\end{array}$ & \\
\hline $\begin{array}{l}\text { Canadian Journal of Nursing } \\
\text { Leadership }\end{array}$ & \\
\hline Canadian Journal of Nursing Research & \\
\hline Canadian Journal of Philosophy & \\
\hline $\begin{array}{l}\text { Canadian Journal of Policy Research } \\
\text { (ISUMA) }\end{array}$ & \\
\hline Canadian Journal of Political Science & \\
\hline Canadian Journal of Public Health & \\
\hline Canadian Journal of Sociology & \\
\hline Canadian Medical Association Journal & \\
\hline Canadian Nurse Journal & \\
\hline Canadian Psychology & \\
\hline Canadian Public Policy & \\
\hline
\end{tabular}

sources was developed with the assistance of a University of Alberta librarian. This list was divided among team members and each team member reviewed the 1995 to 2012 indexes. Each reviewer summarized the findings of selected articles in a table, with the first author then reviewing each of these tables to note common or key findings within and across the tables. These findings were coded, categorized, and then thematically grouped in keeping with common qualitative data analysis techniques. The team as a whole then reviewed and agreed upon the grouped and labelled findings, and the first author drafted a report. The team subsequently reviewed, updated, and eventually approved the final report. This dual process of independent and then group assessment of findings and the analysis of findings augment the trustworthiness of this information development process. 


\section{Results and Discussion}

Three themes among the findings emerged during this literature review: (1) changes in health care and health system reforms after 1994 reduced both the availability and desirability of hospital-based care, (2) sociodemographic developments including aging of the population, increased multiculturalism, and diversity in accepted end-of-life care practices shifted place preferences, and (3) advances in palliative and end-of-life care, including a palliative care expansion out of hospital, supported nonhospital death, and dying processes.

3.1. Changes in Health Care and Health System Reforms after 1994. Health care advancements and health system changes after 1994 supported home-based end-of-life care and reduced the necessity of using hospitals for high quality and accessible end-of-life care.

3.1.1. Health Care Changes. Many new diagnostic tests such as MRI machines, medications, investigative and treatment technologies and surgical techniques became available and were adopted for widespread use after 1994 [9]. These technologies enabled more accurate and earlier diagnoses and improved the capacity to cure or manage acute, chronic, and terminal illnesses [10]. These developments helped make it easier to determine when an illness was terminal or nearing an end stage, thus supporting the shift in care focus from active treatment to palliative or comfort-oriented care. Some new technologies (such as MRI machines) were extremely expensive and these new technologies were understandably only purchased for larger urban hospitals [10]. For rural and small town Canadians, travelling for health care services increased because these new and expensive health care technologies were situated in urban hospitals and the specialists there were also increasingly consulted for complex cases [11].

Health care research also proliferated after 1994 [12], causing increased health care specialization and referrals to medical specialists including palliative care specialists [13]. Evidence-based practice became more normative for health care professionals, health care decision makers, and policy makers [14]; and the widely adopted criteria that all health care practices (old and new) should be evidence-based spurred a major examination of health care services and practices $[15,16]$. Some research caused the discontinuation of useless or harmful practices and the adoption of more successful and effective practices that could often be less costly [9]. Research also increased survival rates including those of cancer patients, and cancer began to be considered a chronic illness in many cases [17].

The evidence-based movement supported what had already become an established practice in Canada of withdrawing and withholding life supporting treatments when they were not appropriate for the patient [18]. A Joint Statement on Resuscitative Interventions was approved in 1995 by four national health care associations and released widely to indicate that futile treatment including cardiopulmonary resuscitation was not appropriate care for terminally ill and dying persons [18]. Evidence increasingly indicated areas where little or no benefit from treatment and the potential for harm and increased or prolonged suffering would occur [19]. A topic that began to be openly discussed was the certainty or eventuality of death for some people, including seriously ill children and very old adults [20, 21]. The 1993 Sue Rodrigues Supreme Court decision to not allow assisted suicide and then her apparent euthanasia in 1994 had a major impact on raising public attention to assisted suicide or euthanasia as potentially legitimate requests of dying persons $[19,22]$. This Supreme Court case also led to two Senate Committee inquiries and reports, the first in 1995 endorsing palliative care so that no dying person would feel a need to ask for hastened death to end their suffering [23] and the second which endorsed the expansion of palliative care into the community [24].

Health care knowledge and technology advances that followed 1994 also permitted a rapid and substantial shift from inpatient hospital-based care to ambulatory or outpatientbased care $[25,26]$. A much smaller proportion of health care procedures continued to require ongoing inpatient-based hospital care $[27,28]$. Home ventilation for people who could not breathe on their own, for example, was considered both possible and common by 2002 [29]. People living with cancer and older people were also impacted by this ambulatory care shift, as they began to incur same-day travel to and from hospitals or clinics to see specialists, have diagnostic tests, receive the results of diagnostic tests and/or hear a prognosis, and then receive outpatient treatments. Travelling for health care services could also involve multiple daily trips, such as for intravenous antibiotic therapy requiring dosing every 612 hours for a week or more. Travelling could also involve multiple hospitals or clinics over the course of an illness. This ambulatory or outpatient shift increased the travelling time and private costs of accessing health care services; with each examination, diagnostic test, and treatment over the course of an illness involving day trips to the same care facilities or to widely varying care venues and locations over the course of an illness or treatment regimen [27].

Terminally ill and dying people were not exempt from this ambulatory health care services development, and with this new travelling burden potentially contributing to active or passive decisions to remain at home. From 1994 to 2000, for instance, a declining proportion of cancer deaths occurred in Canadian hospitals [30]. Cancer has long been associated with significant pain levels and difficult-to-manage symptoms, with the reduction in hospital cancer deaths thus a major indication of the increasing ability to better manage the care of terminally ill or dying people at home but also the problem that travelling for ambulatory health care services is especially impactful on terminally ill and dying persons. The many health care developments and changes that occurred after 1994 thus were considered to have both directly and indirectly impacted terminally ill and dying persons, with a net effect of helping to shift death and dying out of hospitals. These health care developments and changes also impacted the organization and operation of the Canadian health system with implications then for the location of death and dying. 
3.1.2. Health System Reforms. After 1994, health care developments, specialization, the centralization of health care services in larger urban communities, and the shift to ambulatory care rapidly and substantially changed where and how most health care services were provided. These changes, along with economic or fiscal pressures, necessitated health system reforms within Canada. Hospital outpatient clinics and day surgery departments expanded, so that most surgeries and diagnostic tests could be provided without an overnight or extended admission to an inpatient hospital bed $[25,26]$. Community care clinics where outpatients could be cared for by individuals or teams of health care providers [31] and private ambulatory care clinics opened up in the mid to late 1990s across Canada since many tests and treatments could now be done outside of hospital [32]. These health care advances also shortened hospital stays, and with some patients discharged while still needing skilled nursing or supportive care [27, 33, 34]. A considerable proportion of hospital-based health care was thus shifted to the patient's home or nursing home [27, 28]. Home telehealth services were initiated and home care services expanded to accommodate and support the shift of patient care out of hospital [35-39].

Informal caregiver burden began to be researched extensively, in part because inpatient hospital beds and services were less available to provide rehabilitative, respite, subacute, palliative, and supportive care [27]. The wide range and extent of informal care in the home by the children and spouses of older persons, including those suffering from dementia, began to be realized [40, 41]. The federal government enacted the Compassionate Care Act in January 2004 to support those who wanted to take time off work to provide care for a dying family member [42]. Advance directive legislation was also developed in every province by 2000 to support and honor personal preferences in the form of a living will or advanced directive for withholding or withdrawing life support $[43,44]$.

The increased prevalence of chronic or incurable illnesses compared to acute curable or treatable illnesses also became more clearly evident in the years after 1994 [45]. Nurse practitioner programs were developed in part to meet the care needs of chronically ill persons [46-48]. Wellness and health promotion also became increasingly important for preventing chronic illnesses and slowing their progression, with multidisciplinary primary care clinics emerging to address the multiple needs of chronically ill and terminally ill persons [34, 48-52]. These developments in care were accompanied by developments in the health system to support home-based terminal illness care, as more persons began to indicate a preference to die at home [53-56]. The public also took advantage of the rapid increase in health information shared over the Internet, with the public becoming less dependent on health care professionals for information about illnesses, health care services, and health care utility or futility [57].

Three additional major developments after 1994 also had a substantial impact on the Canadian health system as a whole: (a) an economic recession in the 1990 s which led to significant and sustained hospital downsizing despite population growth and aging, (b) nurse shortages, and (c) increased public concern over and criticism about the health system. The 1990s recession occurred at the same time that many new diagnostic tests, medications (some now advertized for the first time on television to raise consumer demand and thus utilization), and surgical and nonsurgical techniques were raising public expectations of health care services and the health system despite the cost-reduction measures that were being initiated by Canadian governments $[32,58]$. Every provincial, territorial, and federal Canadian government took steps in the mid 1990s to address the growing imbalance between government revenue and spending [58]. Public debt had accumulated, with health system financing a major concern for all Canadian governments $[59,60]$. Continually rising health system costs were anticipated because of inflation, a growing and aging population, the need to finance new and often expensive health care technologies, the cost of caring for people with long term chronic illnesses, and the cost of changing an inpatient system to one emphasizing outpatient or ambulatory care services.

In response to these fiscal and other pressures, hospital downsizing was common across Canada; with some hospitals closed and most others sustaining a loss of inpatient beds in the mid to late 1990s [61-64]. Although some provinces such as Alberta closed up to $50 \%$ of their acute care hospital beds by 1997, across Canada 25\% of all acute care inpatient hospital beds were closed by $2000[65,66]$. This grand scale of hospital downsizing meant the remaining hospital beds and hospital emergency departments would often be at overcapacity. The media response to full hospitals and emergency departments and the administrative and practical problems associated with them were important for leading initiatives to ensure that more deaths occurred at home or in nursing homes [67]. Regionalization within provincial health systems was also common across Canada in the mid to late 1990s, with regional boards as governing bodies initiating many health system changes aimed at reducing costs while also trying to improve quality and access to health care services [13].

Health care cost savings were usually achieved with hospital downsizing through nursing workforce reductions, and also reductions in hospital cleaning, maintenance, and supplies or services staff [68]. In the 1990s, nurses and other workers who were laid off often moved out of country or into different types of work [69]. These human resource losses as well as the aging of the health workforce contributed to a shortage of nurses, a problem that became apparent as surgeries were cancelled and wait lists and wait times for health care services increased [10,70,71]. Wait list and wait time issues began to be commonly reported in the media, with public concern over health services accessibility quickly growing during the 1990s and remaining high thereafter [10, 72-74].

Wait lists and wait times also became a focus of considerable government attention, with the federal and provincial governments planning an Accord over the 2002-04 years to reduce wait times and wait lists, and with a 2004-14 Wait Time Reduction Fund set up to target key access delays, including the longer than optimal wait for palliative radiation $[10,70]$. 
The Accord and Fund initiatives followed the release of the National Forum on Health report in 1997 [75], which from 1994 to 1997 had deliberated over ways to improve the health system and the health of Canadians by focusing on long-term trends and systemic issues [76]. Community-based care and evidence-based practice were among the Forum's key recommendations [76]. Following this, the Romanow Commission's [77] cross-Canada investigative work culminated in a 2002 report that made numerous recommendations for health system improvements. The Standing Senate Committee on Social Affairs, Science and Technology (Kirby) Report [78] was also released in 2002, which similarly highlighted health system issues and remedies [79].

Public concern about the health system and health services quality began to appear after 1994, in part because of the nursing shortage but also because of the shift of registered nurse responsibilities to paraprofessional or nonprofessional workers, another cost-reduction measure [68, 77, 80]. Widely noted research reports, ones that highlighted the commonality of medical mistakes or health care errors in Canadian hospitals, helped raise public concern over Canadian health system quality $[80,81]$. The public was directly alerted by stories in major magazines and other media to the issue that health care in hospital could be problematic [82]. The 2002-03 SARS pandemic also emphasized to the public that even the most advanced or high-technology health care in large urban hospitals could not save all afflicted people or even save the nurses and physicians providing care there [83]. These public concerns are thought to have led to considerable growth in the use of natural or alternative health care products and services, sometimes in conjunction with standard Western health care services and sometimes as a replacement [84-86].

The period following 1994 could therefore be described as a troubled historical phase for the Canadian health system. This was clearly a time of considerable system change in keeping with many health care and other developments that served in part to move health care out of inpatient hospital beds. System change was also a result of reduced public access to health care services, health care quality concerns, and other issues that became evident and were the focus of much public and other attention.

3.2. Sociodemographic Developments. Many important sociodemographic developments after 1994 also occurred, and these developments helped to shift death and dying out of hospital. Chief among these developments was population aging, along with a large and growing proportion of the public who were now living with serious long term and usually progressive chronic illnesses [32, 87]. Both population developments were widely noted by researchers and governments across Canada, as well as the public $[3,4,76,77,79]$. It also became evident that the people who died were often older and/or had suffered from one or more incurable illnesses and thus advanced life supporting or aggressive treatmentoriented care was not considered valid or appropriate for them [13]. Available life supports were also not desired now by some afflicted persons, even when one or more might be valid or appropriate for them. Death took place more often in locations other than the hospital as a consequence of wanting to avoid the life supporting technologies that existed in hospital [45].

Death began to be increasingly seen as an event that occurs as expected or as anticipated in advanced old age or an advanced incurable illness state $[21,88]$. The implications of what had been considered the medicalization of common and normal life events such as childbirth and death also began to be discussed, with hospitals and the increasingly advanced life supporting technologies in them viewed more often as optional [88]. The advance directive movement with legislation to formalize living wills or advance directives was in some part driven by terminally ill people who did not want life supports used to prolong their lives $[43,44]$.

Population aging also meant that death usually occurred after age 64 and typically much later, with children in midlife then placed in a position where they could be caring for chronically ill, terminally ill, and/or dying parents for short or substantial periods of time [4]. After 1994, death was often identified as typically involving older persons who often had had 3 or 4 children and some also had a spouse and adult grandchildren, all of whom could be potential informal caregivers $[87,89]$. The traditional socially or family defined duty for family members to provide care for ill and dying family members was clearly evident again [90, 91]. Nontraditional families also became more evident, with caregiving by nontraditional partners and other persons also realized for the first time [92-95]. Research studies began to illustrate the types and hours of in-home care provided by one or more family members and friends [96]. Additional support by family members, often male ones, consisted of providing finances for home maintenance and to purchase in-home care supplies and medications [97]. This "informal" support could also take the form of providing transport so that the afflicted person could access ambulatory health care services. Low income families of dying persons such as new immigrant groups, rural residents, and First Nations groups could lack the funds however to permit travel to urban hospitals and other places for ambulatory or even inpatient health care services, thus making home deaths more likely for them [98-101]. A rural perspective of the "good death" also emerged, one that emphasized the importance of death and dying at home or in the home community [56].

Another development after 1994 was increased multiculturalism, with more nontraditional immigrants such as those from Asia coming to Canada and then tending to settle together in larger cities [102-106]. Much more socially accepted cultural diversity, including awareness of First Nation cultural diversity, occurred [107-111]. Multiculturalism and internationalization were furthered by the globalization of trade, markets, products, and also public viewpoints on major matters $[112,113]$. At the same time, increased interest in personal autonomy or choice became evident $[32,114]$. This development was felt to be a natural consequence of the maturation of the human rights movement that followed the 1982 passage in Canada of the Charter of Rights and Freedoms [115]. The considerable impact of 
the Internet for information sharing about diverse requirements or options for death and dying also began to be understood [85, 116, 117]. Rising concern about natural deaths and good deaths, futile treatments and overtreatment in hospital, and care by strangers in hospital helped to raise the desire for home deaths among dying persons and their families, with palliative care professionals understanding and supporting this desire [56].

The large extent and widespread impact of long-term or chronic and incurable illnesses also became more evident in the years after 1994, with much of the ongoing care associated with chronic illnesses accomplished in the home and often primarily by family caregivers $[46-48,118]$. Chronic illnesses were more common with aging, and population aging thus not only meant an increase in persons of retirement age, but also an increase in chronically ill older persons with supportive care needs from such nonurgent health care needs as advanced old age frailty, dementia, and other chronic diseases such as diabetes [32].

Although population aging was widely known to be occurring across Canada, nursing home expansion was minimal [119]. Instead, assisted-living facilities began to be built [119]. In cases where a person's care needs were extensive and nursing home care was required, nursing home entry was often delayed because of bed shortages until the person was near death [120]. Deaths occurring in nursing homes, assisted living and other rehabilitation care facilities or at home were a natural consequence of this delay. Nonhospital deaths were also increasingly occurring because advance directives or advance care planning was prohibiting life support in hospital. Full hospitals and crowded emergency departments served to prohibit transfer there from nursing homes and other care facilities, and this knowledge also impacted the care relocation decisions made by home-based dying persons and their families. Thus many important socio-demographic developments after 1994 were important for helping to shift death and dying out of hospital.

3.3. Palliative and End-of-Life Care Advancements. Following 1994, specialist palliative care advancements and equally important basic end-of-life care developments were common. Although specialist palliative care had become established as a service in most large Canadian hospitals by 1994 through in-hospital palliative care units and/or palliative care teams, the palliative care developments that occurred after 1994 were important for helping to shift death, dying and endof-life care out of hospital [13]. Chief among these was the expansion of palliative care programs from larger hospitals to smaller regional areas or to province-wide services that permitted hospital discharge through facilitating home-based or nursing home-based end-of-life care and death [13, 121, 122]. Home care services began to provide for the ongoing care of persons with terminal illnesses and support for dying at home [123-125]. Improved pain control, care coordination advice, and assistance from registered nurses who were now often palliative home care specialists, and a range of family supports such as respite care emerged or expanded in this era $[116,126,127]$.

Although few in number, hospices also began to be built after 1994 to provide an alternative location for the provision of palliative care. In 1995, the first Canadian hospice for children, Canuck Place, was opened in Vancouver, British Columbia [128]. Palliative care specialization and expansion occurred throughout and after the 1990s, particularly through the efforts of the Secretariat on Palliative and End-of-Life Care, a group established by the federal government in 2001 [13]. This group continued working until 2007 when it was disbanded to enhance the growth of specialized palliative care services, the number of specialized providers and palliative research investigations, the visibility of the Canadian Hospice Palliative Care Association after its creation in 1991, and for palliative care to be recognized as a core health service [13]. Palliative care physicians and nurse specialists increased in number, and smaller communities were able to initiate palliative care services through either directly employing specialists or having visiting specialists come to the community [13].

Palliative care research also proliferated in this era [129], with evidence-based information increasing, including the information that many terminally ill persons wished for or were planning a home-based death [53-56]. Research developments also helped to reduce fear of pain and other symptoms when dying, in part because they were successful in reducing pain and other distressing symptoms-a major consideration for successfully shifting death and dying out of hospital. Palliative information sharing increased, with this information also going to professional entry-level health care education programs so that all newly graduated nurses and other health care professionals would have baseline palliative knowledge and skills [125]. This information was also made available to the public through the Internet. As of February 2004, the Canadian Virtual Hospice became a major open online source of palliative care information [130].

In many provinces, palliative home care was initiated or expanded after 1994 to support home-based clients [124, 125]. Home care expansion was also evident after 1994 to support the more basic care needs of failing chronically ill and/or very old persons at home $[131,132]$. Similarly, nursing homes and other senior care complexes began to deliver end-oflife care or allow palliative home care nurses to enter to provide in-house care whereas previously the dying person would have been transferred to a hospital for end-of-life care [28]. This end-of-life care episode could now include substantial end-stage support so that the death would take place in the home or nursing care facility, as do-not resuscitate orders and advance care documents stating a refusal of a transfer to hospital became more common [133-136]. What was said to be a long-standing public fear of dying and the public avoidance of dying persons were now being replaced by open death preparation in the home or the normal place of residence [137-139]. These are important end-oflife care developments, ones in keeping with palliative care developments that similarly served to support the shift of death and dying out of hospital. 


\section{Conclusions}

This integrative review report outlines a literature search and analysis process that was designed and conducted to discover the factors or influences for the shift of death and dying out of Canadian hospitals after 1994. An interwoven set of many distinct factors were identified as contributing to this out-of-hospital shift, including multiple health care and health system changes, socio-demographic developments, and palliative or end-of-life care advancements. More people began to receive basic end-of-life care and specialist palliative care in homes and nursing homes in part because hospitals became a less accessible place of care as well as a less desirable care setting for dying loved ones. Homes and nursing homes began to be a more possible and more desired place for end-of-life care, with families often extensively engaged in providing end-of-life care outside the hospital setting. Socio-demographic developments were also important, with many different social, societal, and other Canadawide factors influencing the location of death and dying. Considerable advances in palliative care specialization and palliative research developments occurred after 1994, with these supporting nonhospital dying processes and thus death out of hospital.

As such, it became evident through this review that an out-of-hospital shift in Canada was the result of many indirect and direct influences or factors that contributed to death and dying in other places. Future research should focus on the supports needed to ensure good deaths occur in all such places and that individuals are dying in the appropriate place. Abuse and unmet needs in the home or other nonhospital care facilities may go undetected. With low staffing levels and less qualified staff in nursing homes being asked to take on more caregiving responsibility, research is also needed now to determine how best to ensure high quality dying processes in nursing homes. Research and knowledge transfer about the benefits of nonhospital deaths are also needed now, as this shift out of hospital could reverse and hospitals once again could become the predominant place of death and dying. While the shift out of Canadian hospitals after 1994 was neither directly planned for, anticipated, nor supported by government policy, the maintenance of this shift is likely to need government policy in the years ahead as the number of deaths increases dramatically in Canada. The large baby boom generation has begun to reach old age and many will require end-of-life care in one form or another.

In closing, although this literature review was exclusively focused on Canadian literature and Canadian events or developments, many of these events and developments could have also occurred in other developed and possibly some developing countries. These same factors and influences could be initiating or supporting an out-of-hospital shift elsewhere, as Canada is not the only country where this out-of-hospital shift has occurred $[1,6,7]$. Other factors or influences on location of death may also be impactful. These are important to understand in our quest to ensure high quality and compassionate end-of-life care for all terminally ill and dying people.

\section{Conflict of Interests}

The authors declare that there is no conflict of interests regarding the publication of this paper.

\section{References}

[1] K. Meeussen, L. van den Block, M. A. Echteld et al., "Endof-Life care and circumstances of death in patients dying as a result of cancer in Belgium and The Netherlands: a retrospective comparative study," Journal of Clinical Oncology, vol. 29, no. 32, pp. 4327-4334, 2011.

[2] D. M. Wilson, "The duration and degree of end-of-life dependency of home care clients and hospital inpatients," Applied Nursing Research, vol. 15, no. 2, pp. 81-86, 2002.

[3] D. M. Wilson, H. C. Northcott, C. D. Truman et al., "Location of death in Canada: a comparison of 20th-century hospital and nonhospital locations of death and corresponding population trends," Evaluation and the Health Professions, vol. 24, no. 4, pp. 385-403, 2001.

[4] D. M. Wilson, C. D. Truman, R. Thomas et al., "The rapidly changing location of death in Canada, 1994-2004," Social Science and Medicine, vol. 68, no. 10, pp. 1752-1758, 2009.

[5] Statistics Canada, "Deaths by geography-in hospital or elsewhere," 2012, http://www.statcan.gc.ca/pub/84f0211x/2008000/ t012-eng.htm.

[6] B. Gomes, N. Calanzani, and I. J. Higginson, "Reversal of the British trends in place of death: time series analysis 2004-2010," Palliative Medicine, vol. 26, no. 2, pp. 102-107, 2012.

[7] S. M. Hansen, S. W. Tolle, and D. P. Martin, "Factors associated with lower rates of in-hospital death," Journal of Palliative Medicine, vol. 5, no. 5, pp. 677-685, 2002.

[8] R. J. Torraco, "Writing integrative literature reviews: guidelines and examples," Human Resource Development Review, vol. 4, no. 3, pp. 356-367, 2005.

[9] L. Di Matteo and R. Di Matteo, "Public Homecare expenditures in Canada," Canadian Public Policy, vol. 27, no. 3, pp. 313-334, 2001.

[10] D. J. Emery, A. J. Forster, K. G. Shojania, M. Tubman, and T. E. Feasby, "Management of MRI wait lists in Canada," Health Care Policy, vol. 4, no. 3, pp. 76-86, 2009.

[11] J. T. McDonald and H. Conde, "Does geography matter? the health service use and unmet health care needs of older Canadians," Canadian Journal on Aging, vol. 29, no. 1, pp. 2337, 2010.

[12] C. L. McWilliam, "Sharpening the focus of research on in-home and community care for older persons," Canadian Journal of Nursing Research, vol. 40, no. 1, pp. 5-8, 2008.

[13] A. M. Williams, V. A. Crooks, K. Whitfield et al., "Tracking the evolution of hospice palliative care in Canada: a comparative case study analysis of seven provinces," BMC Health Services Research, vol. 10, article 147, 2010.

[14] A. DiCenso, "Evidence-based nursing practice: how to get there from here," Canadian Journal of Nursing Leadership, vol. 16, no. 4, pp. 20-26, 2003.

[15] H. B. MacDonald, "Milk products: an investment in one's future," Canadian Nurse, vol. 99, no. 6, article 8, 2003.

[16] B. Simpson, "Evidence-based nursing practice: the state of the art," Canadian Nurse, vol. 92, no. 10, article 29, pp. 22-25, 1996.

[17] M. Nichols, "Cancer mortality rates in Canada," Maclean'S Magazine, vol. 112, no. 43, 1999. 
[18] M. R. McIntyre, "Understanding living with dying," Canadian Nurse, vol. 93, no. 1, pp. 19-25, 1997.

[19] M. A. Achille and J. R. P. Ogloff, "When is a request for assisted suicide legitimate? Factors influencing public attitudes toward euthanasia," Canadian Journal of Behavioural Science, vol. 29, no. 1, pp. 19-27, 1997.

[20] B. Parke and J. Mulgrew, "End-of-life care in old age," Canadian Nurse, vol. 96, no. 9, pp. 12-13, 2000.

[21] R. G. Steele, "Trajectory of certain death at an unknown time: children with neurodegenerative life-threatening illnesses," Canadian Journal of Nursing Research, vol. 32, no. 3, pp. 49-67, 2000.

[22] G. Boscoe, "Active euthanasia," Canadian Nurse, vol. 94, no. 6, pp. 13-14, 1998.

[23] Special Senate Committee on Euthanasia and Assisted Suicide, "Of life and death-final report," 1995, http://www.parl.gc.ca/ content/sen/committee/351/euth/rep/lad-e.htm.

[24] Standing Senate Committee on Social Affairs, Science and Technology, "Subcommittee to update, 'of life and death"' Quality end-of-life care: the right of every Canadian, 2000, http://www.parl.gc.ca/Content/SEN/Committee/362/upda/rep /repfinjun00-e.htm.

[25] B. Mildon, L. Shepard, and G. Hozack, "Hospital without walls," Canadian Nurse, vol. 94, no. 9, pp. 31-34, 1998.

[26] M. Sutherland and B. Bruce, "Same-day pediatric surgery," Canadian Nurse, vol. 94, no. 4, pp. 36-39, 1998.

[27] S. A. McDaniel, "Health care policy in an aging Canada: the "Alberta" experiment," Journal of Aging Studies, vol. 11, no. 3, pp. 211-227, 1997.

[28] M. J. McGregor, R. B. Tate, L. A. Ronald, and K. M. McGrail, "Variation in site of death among nursing home residents in British Columbia, Canada," Journal of Palliative Medicine, vol. 10, no. 5, pp. 1128-1136, 2007.

[29] E. Alexander, J. E. Rennick, F. Carnevale, and M. Davis, "Daily struggles: living with long-term childhood technology dependence," Canadian Journal of Nursing Research, vol. 34, no. 4, pp. 7-14, 2002.

[30] C. I. Neutel, M. L. Bishop, S. D. Harper, and L. A. Gaudette, "Proportion of cancer deaths occuring in hospital, Canada 1994-2000," Canadian Journal of Public Health, vol. 96, no. 4, pp. 264-268, 2005.

[31] S. M. Gallagher, M. Relf, and R. McKim, "Primary health care. Integrated services in northeast Edmonton," Canadian Nurse, vol. 99, no. 1, pp. 25-29, 2003.

[32] N. C. Keating, "Bridging policy and research in eldercare," Canadian Journal on Aging/Canadian Public Policy, vol. 23, pp. 22-41, 1997.

[33] M. Collins and V. MacDonald, "Managing postoperative pain at home," Canadian Nurse, vol. 96, no. 7, pp. 26-29, 2000.

[34] D. L. Wells, D. K. Martin, A. Moorhouse, D. Craig, and J. M. Foley, "An integrated model of discharge planning for acutelyill elderly patients," Canadian Journal of Nursing Leadership, vol. 12, no. 3, pp. 6-12, 1999.

[35] Canadian Nurses Association, "Telehealth: great potential or risky terrain?” Canadian Nurse, vol. 96, no. 10, pp. 5-8, 2000.

[36] S. Goodwin, "Telephone nursing: an emerging practice area," Canadian Journal of Nursing Leadership, vol. 20, no. 4, pp. 3745, 2007.

[37] S. Griffin and B. Layton, "Bringing care closer to home," Canadian Nurse, vol. 104, no. 6, pp. 12-13, 2008.
[38] B. Korabek, C. Slauenwhite, P. Rosenau, and L. Ross, "Innovations in seniors' care: home care/physician partnership," Canadian Journal of Nursing Leadership, vol. 17, no. 3, pp. 6578, 2004.

[39] L. M. Nagle, "Show me the way to stay home," Canadian Journal of Nursing Leadership, vol. 21, no. 4, pp. 29-32, 2008.

[40] P. G. Hawranik and L. A. Strain, "Giving voice to informal caregivers of older adults," Canadian Journal of Nursing Research, vol. 39, no. 1, pp. 156-172, 2007.

[41] S. C. Peacock and D. A. Forbes, "Interventions for caregivers of persons with dementia: a systematic review," Canadian Journal of Nursing Research, vol. 35, no. 4, pp. 88-107, 2003.

[42] Department of Justice, Canada Labour Code (R.S., 1985, c. L-2), 2010, http://laws.justice.gc.ca/en/L-2/FullText.html.

[43] M. Hurst, "About the living will," Canadian Nurse, vol. 101, no. 4, p. 4, 2005.

[44] C. Patterson, D. W. Molloy, G. H. Guyatt et al., "Systematic implementation of an advance health care directive in the community," Canadian Journal of Nursing Administration, vol. 10, no. 2, pp. 96-108, 1997.

[45] S. S. Motiwala, R. Croxford, D. N. Guerriere, and P. C. Coyte, "Predictors of place of death for seniors in Ontario: a population-based cohort analysis," Canadian Journal on Aging, vol. 25, no. 4, pp. 363-371, 2006.

[46] V. Micevski, L. Korkola, S. Sarkissian et al., "University Health Network framework for advanced nursing practice: development of a comprehensive conceptual framework describing the multidimensional contributions of advanced practice nurses," Canadian Journal of Nursing Leadership, vol. 17, no. 3, pp. 5264, 2004.

[47] P. Pogue, "The nurse practitioner role: into the future," Canadian Journal of Nursing Leadership, vol. 20, no. 2, pp. 35-39, 2007.

[48] S. Sidani, D. Irvine, and A. DiCenso, "Implementation of the primary care nurse practitioner role in Ontario," Canadian Journal of Nursing Leadership, vol. 13, no. 3, pp. 13-19, 2000.

[49] H. Broughton, "The shift to wellness," Canadian Nurse, vol. 91, no. 7, p. 5, 1995.

[50] G. Hartrick, D. Brown, M. Eastman et al., "The synergy of health promotion practice/research/education," Canadian Journal of Nursing Leadership, vol. 12, no. 4, pp. 25-29, 1999.

[51] R. Martin-Misener, J. McNab, I. S. Sketris, and L. Edwards, "Collaborative practice in health systems change: the Nova Scotia experience with the Strengthening Primary Care Initiative," Canadian Journal of Nursing Leadership, vol. 17, no. 2, pp. 33-45, 2004.

[52] C. Todd, M. Howlett, M. MacKay, and B. Lawson, "Family practice/primary health care nurses in Nova Scotia," Canadian Nurse, vol. 103, no. 6, pp. 23-27, 2007.

[53] K. Brazil, D. Howell, M. Bedard, P. Krueger, and C. Heidebrecht, "Preferences for place of care and place of death among informal caregivers of the terminally ill," Palliative Medicine, vol. 19, no. 6, pp. 492-499, 2005.

[54] K. I. Stajduhar, D. E. Allan, S. R. Cohen, and D. K. Heyland, "Preferences for location of death of seriously ill hospitalized patients: perspectives from Canadian patients and their family caregivers," Palliative Medicine, vol. 22, no. 1, pp. 85-88, 2008.

[55] D. Wilson, J. Cohen, L. Deliens, and D. Houttekier, “The preferred place of last days: results of a representative populationbased survey," Journal of Palliative Medicine, vol. 16, no. 5, 2013.

[56] D. M. Wilson, L. Fillion, R. Thomas, C. Justice, P. P. Bhardwaj, and A.-M. Veillette, "The "good" rural death: a report of 
an ethnographic study in Alberta, Canada," Journal of Palliative Care, vol. 25, no. 1, pp. 21-29, 2009.

[57] L. M. Nagle, "Informatics around the globe," Canadian Journal of Nursing Leadership, vol. 22, no. 3, pp. 21-25, 2009.

[58] P. Fortin, "The great Canadian slump," Canadian Journal of Economics, vol. 29, no. 4, pp. 761-787, 1996.

[59] J. Aronson and S. M. Neysmith, "Manufacturing social exclusion in the home care market," Canadian Public Policy, vol. 27, no. 2, pp. 151-165, 2001.

[60] L. Boon, "Caring practices and the financial bottom line," Canadian Nurse, vol. 94, no. 3, pp. 27-32, 1998.

[61] A. Casebeer, C. Scott, and K. Hannah, "Transforming a health care system: managing change for community gain," Canadian Journal of Public Health, vol. 91, no. 2, pp. 89-93, 2000.

[62] L. Liu, J. Hader, B. Brossart, R. White, and S. Lewis, "Impact of rural hospital closures in Saskatchewan, Canada," Social Science and Medicine, vol. 52, no. 12, pp. 1793-1804, 2001.

[63] M. J. Penning, M. E. Brackley, and D. E. Allan, "Home care and health reform: changes in home care utilization in one Canadian province, 1990-2000," Gerontologist, vol. 46, no. 6, pp. 744-758, 2006.

[64] M. Armstrong-Stassen, S. J. Cameron, J. Mantler, and M. E. Horsburgh, "The impact of hospital amalgamation on the job attitudes of nurses," Canadian Journal of Administrative Sciences, vol. 18, no. 3, pp. 149-162, 2001.

[65] R. J. Burke, "Restructuring stressors and perceived hospital effectiveness," Canadian Journal of Nursing Leadership, vol. 14, no. 1, pp. 21-26, 2001.

[66] I. Daiski, "Restructuring: a view from the bedside," Canadian Journal of Nursing Leadership, vol. 17, no. 3, pp. 33-44, 2004.

[67] D. G. Morgan, N. J. Stewart, C. D’Arcy, and A. L. Cammer, "Creating and sustaining dementia special care units in rural nursing homes: the critical role of nursing leadership," Canadian Journal of Nursing Leadership, vol. 18, no. 2, pp. 74-99, 2005.

[68] A. Landesman, "Restructuring hospitals, restructuring nursing," Canadian Nurse, vol. 92, no. 2, pp. 27-30, 1996.

[69] L. Little, "Nurse migration: a Canadian case study, Health Services Research, vol. 42, no. 3, pp. 1336-1353, 2007.

[70] S. Regan, S. Thorne, and B. Mildon, "Uncovering blind spots in education and practice leadership: towards a collaborative response to the nurse shortage," Canadian Journal of Nursing Leadership, vol. 22, no. 2, pp. 30-40, 2009.

[71] S. D. Smith, "The need for a national nursing strategy," Canadian Journal of Nursing Leadership, vol. 13, no. 2, p. 4, 2000.

[72] M. Fletcher, "Pollara survey: Canadians more concerned about health care system," Canadian Nurse, vol. 98, no. 1, article 10, 2002.

[73] M. Harris and V. Richman, "Health care delivery. The waiting list reality," Canadian Nurse, vol. 98, no. 4, pp. 16-20, 2002.

[74] J. M. Trypuc and A. R. Hudson, "Waiting lists and nursing," Canadian Journal of Nursing Leadership, vol. 18, no. 4, pp. 3640, 2005.

[75] Health Canada, "Canada health action, building on the legacy," 2004, http://www.hc-sc.gc.ca/hcs-sss/pubs/renewal-renouv/ 1997-nfoh-fnss-v1/index-eng.php.

[76] J. Ritchie, "Whatever happened to the national forum on health?. Interview by Barbara Sibbald," Canadian Nurse, vol. 94, no. 2, pp. 24-26, 1998.

[77] R. J. Romanow, "Building on values: the future of health care in Canada," 2002, http://www.hc-sc.gc.ca/hcs-sss/hhr-rhs/strateg /romanow-eng.php.
[78] Standing Senate Committee on Social Affairs, Science and Technology, "Subcommittee to update, "Of life and death." Quality end-of-life care: the right of every Canadian," 2000, http://www.parl.gc.ca/Content/SEN/Committee/362/upda/rep /repfinjun00-e.htm.

[79] Parliament of Canada, "The health of Canadians-the federal role. Final report," 2002, http://www.parl.gc.ca/content/ sen/committee/372/soci/rep/repoct02vol6-e.htm.

[80] W. Nicklin, H. Mass, D. D. Affonso et al., "Patient safety culture and leadership within Canada's Academic Health Science Centres: towards the development of a collaborative position paper," Canadian Journal of Nursing Leadership, vol. 17, no. 1, pp. 22-34, 2004.

[81] G. R. Baker, P. G. Norton, V. Flintoft et al., "The Canadian adverse events study: the incidence of adverse events among hospital patients in Canada," Canadian Medical Association Journal, vol. 170, no. 11, pp. 1678-1686, 2004.

[82] "Engelhart M. The heart of the matter: why surviving cardiac arrest in Canada is so difficult.", Maclean's Magazine, September 2009, http://www2.macleans.ca/2009/09/10 /the-heart-of-the-matter/.

[83] J. M. Conly and B. L. Johnston, "SARS: a tale of two epidemics," Canadian Journal of Infectious Diseases, vol. 14, no. 3, pp. 147149, 2003.

[84] M. Fletcher, "More elderly women use herbal products but don't tell health care providers," Canadian Nurse, vol. 97, no. 4, article 10, 2001.

[85] J. McClennon-Leong and J. R. Kerr, "Alternative health care options in Canada," Canadian Nurse, vol. 95, no. 10, pp. 26-30, 1999.

[86] L. Tropmann, T. Johns, and K. Gray-Donald, "Natural health product use in Canada," Canadian Journal of Public Health, vol. 93, no. 6, pp. 426-430, 2002.

[87] J. Keefe, J. Légaré, and Y. Carrière, “Developing new strategies to support future caregivers of older Canadians with disabilities: projections of need and their policy implications," Canadian Public Policy, vol. 33, pp. S65-S80, 2007.

[88] D. M. Wilson, J. Cohen, S. Birch et al., "No one dies of old age': implications for research, practice, and policy," Journal of Palliative Care, vol. 27, no. 2, pp. 148-156, 2011.

[89] E. Latif, "Labour supply effects of informal caregiving in Canada," Canadian Public Policy, vol. 32, no. 4, pp. 413-429, 2006.

[90] J. Alexander, "Theorizing the good society: hermeneutic, normative and empirical discourses," Canadian Journal of Sociology, vol. 25, no. 3, pp. 271-309, 2000.

[91] Z. Bauman, "Ethics of individuals," Canadian Journal of Sociology, vol. 25, no. 1, pp. 83-96, 2000.

[92] L. Beaman, "Sexual orientation and legal discourse: legal constructions of the, "normal" family," Canadian Journal of Law and Society, vol. 14, no. 2, pp. 173-202, 1999.

[93] D. G. Casswell, "Moving toward same-sex marriage," Canadian Bar Review, vol. 80, no. 3, pp. 810-857, 2001.

[94] S. Gavigan, "Legal forms and family norms: what is a spouse?" Canadian Journal of Law and Society, vol. 14, no. 1, pp. 127-158, 1999.

[95] A. H. Young, "The changing family, rights discourse and the Supreme Court of Canada," Canadian Bar Review, vol. 80, no. 1-2, pp. 749-793, 2001.

[96] A. Colantonio, A. J. Kositsky, C. Cohen, and L. Vernich, "What support do caregivers of elderly want? Results from 
the Canadian Study of Health and Aging," Canadian Journal of Public Health, vol. 92, no. 5, pp. 376-379, 2001.

[97] V. A. Crooks, A. Williams, K. I. Stajduhar, D. E. Allan, and S. R. Cohen, "The information transfer and knowledge acquisition geographies of family caregivers: an analysis of Canada's compassionate care benefit," Canadian Journal of Nursing Research, vol. 39, no. 3, pp. 36-54, 2007.

[98] C. Dempsey, "Elderly immigrants in Canada: income sources and self-sufficiency," Canadian Issues, vol. 44, 2005.

[99] D. W. L. Lai and S. Surood, "Types and factor structure of barriers to utilization of health services among aging South Asians in Calgary, Canada," Canadian Journal on Aging, vol. 29, no. 2, pp. 249-258, 2010.

[100] S. G. Prus, R. Tfaily, and Z. Lin, "Comparing racial and immigrant health status and health care access in later life in Canada and the United States," Canadian Journal on Aging, vol. 29, no. 3, pp. 383-395, 2010.

[101] M. Stewart, L. Reutter, E. Makwarimba et al., "Determinants of health-service use by low-income people," Canadian Journal of Nursing Research, vol. 37, no. 3, pp. 104-131, 2005.

[102] P. W. R. Bowlby, "Diasporic religions in Canada: opportunities and challenges," Canadian Issues, vol. 1, 2003.

[103] V. Danyluk, "Major cities in the 21st century," Canadian Issues, vol. 1, 2003.

[104] L. Driedger, "Immigrant/ethnic/racial segregation: Canadian big three and prairie metropolitan comparison," Canadian Journal of Sociology, vol. 24, no. 4, pp. 485-509, 1999.

[105] D. Hiebert, "Immigration and the changing Canadian cities," Canadian Geographer, vol. 1, 2003.

[106] D. Norris and C. Bryant, "Demographic change in Canada's urban areas: results from the 2001 census," Canadian Issues, vol. $1,2001$.

[107] S. Guruge and G. Donner, "Transcultural nursing in Canada," Canadian Nurse, vol. 92, no. 8, pp. 36-40, 1996.

[108] Statistics Canada, "Immigration and ethnocultural diversity in Canada," 2011, http://wwwl2.statcan.gc.ca/nhs-enm/2011/assa/99-010-x99-010-x2011001-eng.cfm.

[109] C. Trainsnel, "Combining local distinctiveness and cultural diversity: immigration and cultural diversity in the identify discourse of nationalisms of protest in Quebec. Acadaia and Wallonia," Canadian Issues, pp. 34-39, 2008.

[110] B. Vissandjée, P. Carignan, and M. Bourdeau-Marchand, "New immigrant women and health," Canadian Nurse, vol. 95, no. 4, pp. 35-41, 1999.

[111] D. S. Whalen, "Commentary: cultural sensitivity: a matter of respect," Canadian Nurse, vol. 95, no. 9, pp. 43-44, 1999.

[112] S. N. Eisenstadt, "Note on society/note société: multiple modernities in an age of globalization," Canadian Journal of Sociology, vol. 24, no. 2, p. 283, 1999.

[113] M. R. Nakhaie and R. M. Pike, "Social origins, social statuses and home computer access and use," Canadian Journal of Sociology, vol. 23, no. 4, pp. 427-450, 1998.

[114] M. A. Bakitas, "Self-determination: analysis of the concept and implications for research in palliative care," Canadian Journal of Nursing Research, vol. 37, no. 2, pp. 22-49, 2005.

[115] J. Haines, "Giving human rights a helping hand," Canadian Nurse, vol. 94, no. 10, p. 3, 1998.

[116] M. Fletcher, “Manifesto' promotes better pain management," Canadian Nurse, vol. 97, no. 6, 2001.

[117] J. Jedwab, "Internet use and Canadian cultural choices," Canadian Issues, pp. 41-48, 2007.
[118] C. Jillings and S. Thorne, "Shifting the rhythm of chronic illness care," Canadian Journal of Nursing Research, vol. 40, no. 3, pp. $5-6,2008$.

[119] S. M. Dupuis-Blanchard, "Building a new nest: the experience of women relocating to a seniors-designated apartment building," Canadian Journal of Nursing Research, vol. 39, no. 4, pp. 136-153, 2007.

[120] D. M. Wilson and C. D. Truman, "Long-term-care residents," Canadian Journal of Public Health, vol. 95, no. 5, pp. 382-386, 2004.

[121] K. Fassbender, R. Fainsinger, C. Brenneis, P. Brown, T. Braun, and P. Jacobs, "Utilization and costs of the introduction of system-wide palliative care in Alberta, 1993-2000," Palliative Medicine, vol. 19, no. 7, pp. 513-520, 2005.

[122] B. J. Lawson, F. I. Burge, P. McIntyre, S. Field, and D. Maxwell, "Can the introduction of an integrated service model to an existing comprehensive palliative care service impact emergency department visits among enrolled patients?" Journal of Palliative Medicine, vol. 12, no. 3, pp. 245-252, 2009.

[123] D. Wilson, C. D. Truman, J. Huang, S. Sheps, R. Thomas, and T. Noseworthy, "The possibilities and the realities of home care," Canadian Journal of Public Health, vol. 96, no. 5, pp. 385-389, 2005.

[124] D. M. Wilson, C. Truman, J. Huang et al., "Home care evolution in Alberta: how have palliative clients fared?" Health Care Policy Journal, vol. 2, no. 4, pp. 44-56, 2007.

[125] D. Wilson, B. Goodwin, and J. Hewitt, "An examination of death education in introductory nursing programs across Canada," Nursing Research and Practice, vol. 2011, Article ID 907172, 5 pages, 2011.

[126] L. Atack and R. Kenny, "Care co-ordination. An expanded role for nurses," Canadian Nurse, vol. 94, no. 7, pp. 41-45, 1998.

[127] J. Chobanuk, E. Pituskin, L. Kashuba, and J. Bates, "Telephone triage in acute oncology," Canadian Nurse, vol. 95, no. 1, pp. 3032, 1999.

[128] B. Davies, B. Eng, R. Arcand, J. Collins, and N. Bhanji, "Canuck place: a hospice for dying children," Canadian Nurse, vol. 92, no. 4, pp. 22-25, 1996.

[129] G. M. Johnston, F. I. Burge, C. J. Boyd, and M. MacIntyre, "Endof-life population study methods," Canadian Journal of Public Health, vol. 92, no. 5, pp. 385-386, 2001.

[130] M. Fletcher, "Canadian virtual hospice service reaches out," Canadian Nurse, vol. 100, no. 3, article 16, 2004.

[131] M. B. Harrison, C. Toman, and J. Logan, "Hospital to home evidence-based education for CHF," Canadian Nurse, vol. 94, no. 2, pp. 36-42, 1998.

[132] A. G. Tilley, "Caregivers of elderly parents at home," Canadian Nurse, vol. 92, no. 2, article 19, 1996.

[133] P. Brink, T. F. Smith, and M. Kitson, "Determinants of do-notresuscitate orders in palliative home care," Journal of Palliative Medicine, vol. 11, no. 2, pp. 226-232, 2008.

[134] F. Burge, B. Lawson, and G. Johnston, "Trends in the place of death of cancer patients, 1992-1997," Canadian Medical Association Journal, vol. 168, no. 3, pp. 265-270, 2003.

[135] I. R. McWhinney, M. J. Bass, and V. Orr, "Factors associated with location of death (home or hospital) of patients referred to a palliative care team," Canadian Medical Association Journal, vol. 152, no. 3, pp. 361-367, 1995.

[136] V. H. Menec, S. Nowicki, A. Blandford, and D. Veselyuk, "Hospitalizations at the end of life among long-term care residents," Journals of Gerontology A, vol. 64, no. 3, pp. 395-402, 2009. 
[137] P. Cantwell, S. Turco, C. Brenneis, J. Hanson, C. M. Neumann, and E. Bruera, "Predictors of home death in palliative care cancer patients," Journal of Palliative Care, vol. 16, no. 1, pp. 23$28,2000$.

[138] K. Chunlestskul, L. E. Carlson, J. R. Koopmans, and M. J. Angen, "Lived experiences of Canadian women with metastatic breast cancer in preparation for their death: a qualitative study. Part II: enabling and inhibiting factors; the paradox of death preparation," Journal of Palliative Care, vol. 24, no. 1, pp. 16-25, 2008.

[139] J. U. Vohra, K. Brazil, S. Hanna, and J. Abelson, "Family perceptions of end-of-life care in long-term care facilities," Journal of Palliative Care, vol. 20, no. 4, pp. 297-302, 2004. 


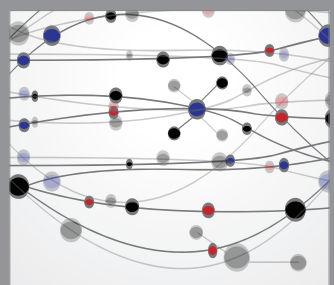

The Scientific World Journal
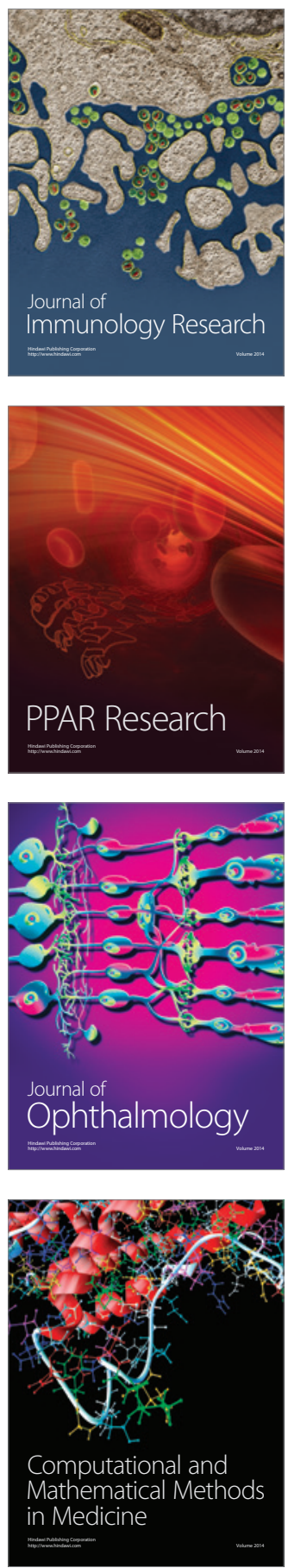

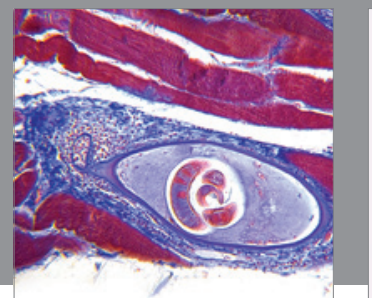

Gastroenterology

Research and Practice
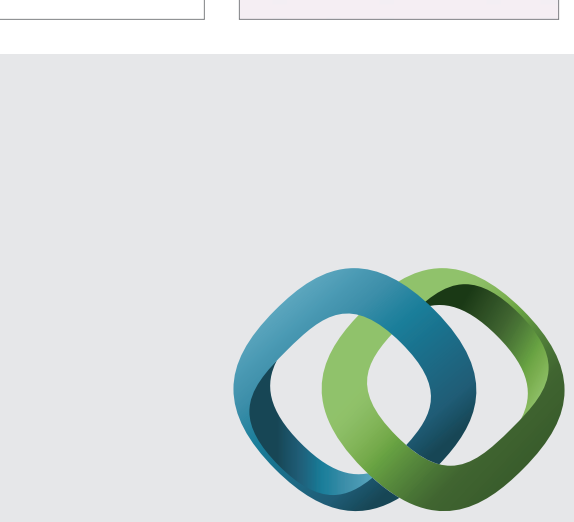

\section{Hindawi}

Submit your manuscripts at

http://www.hindawi.com
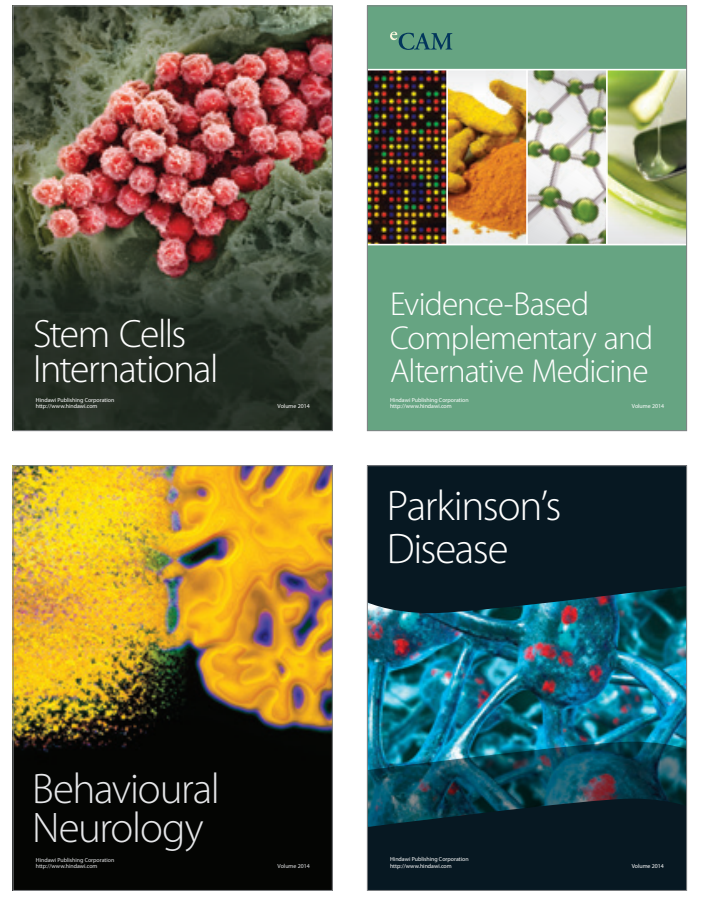
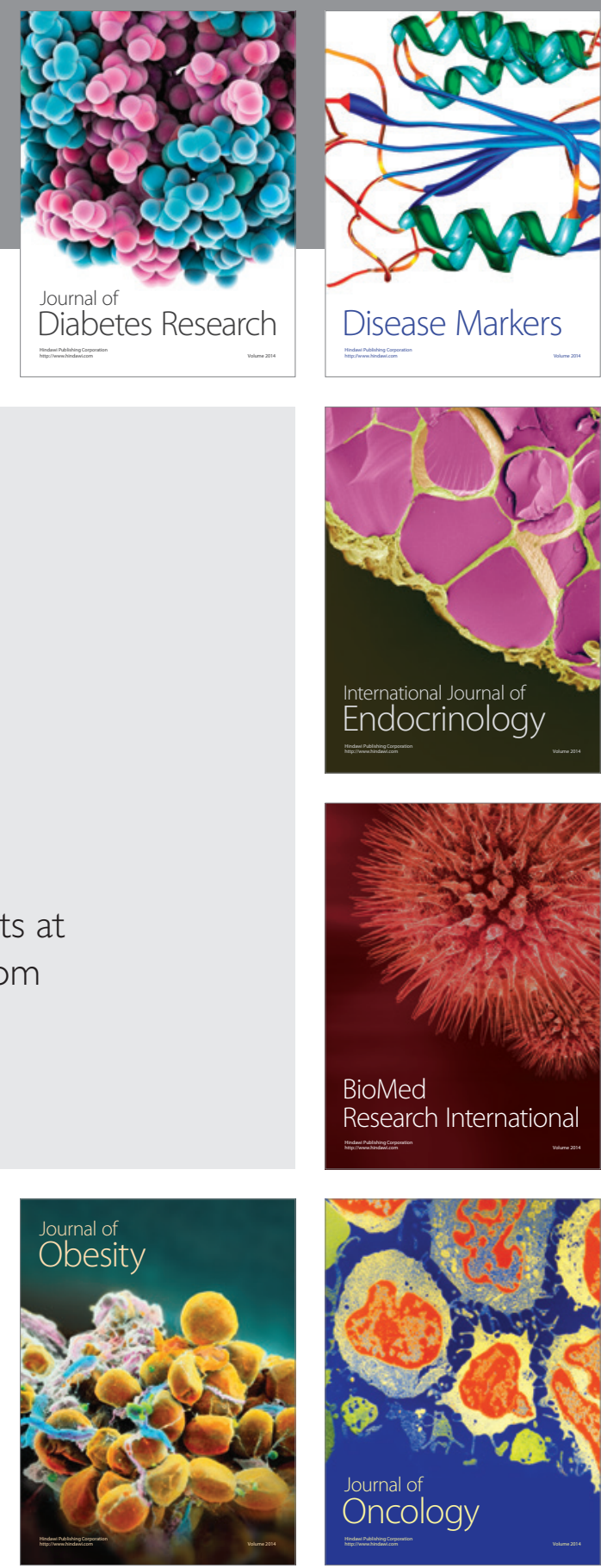

Disease Markers
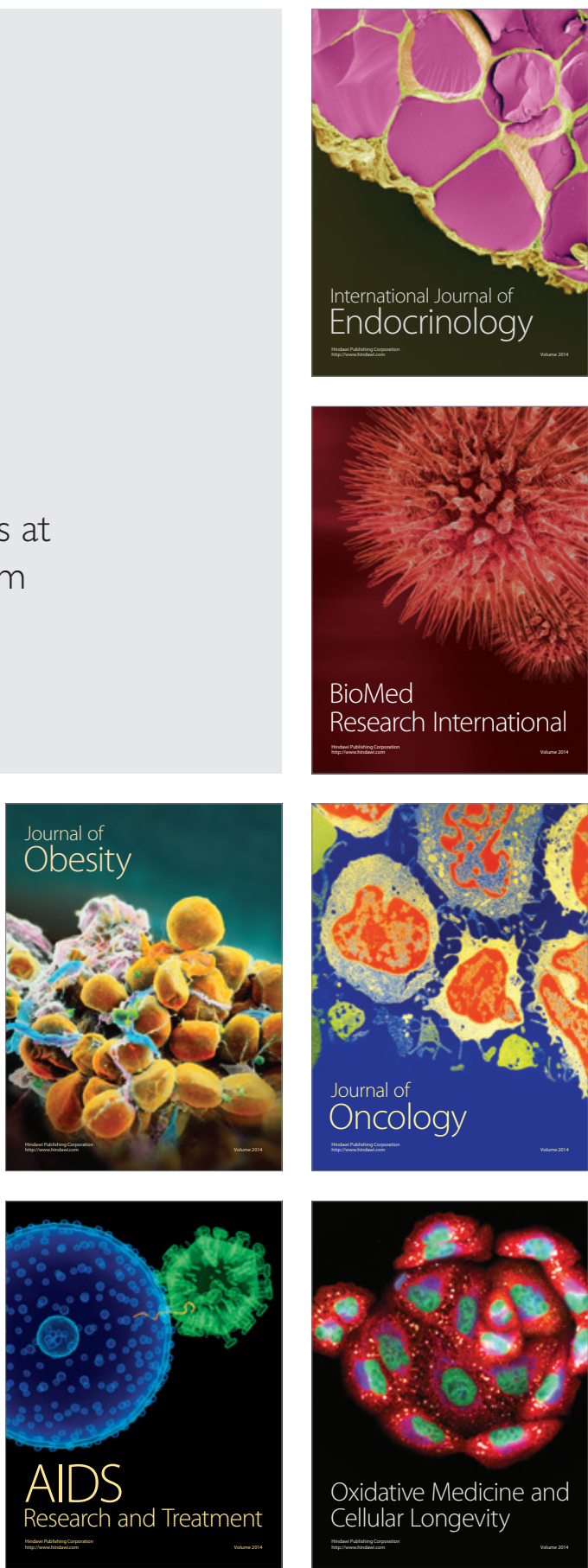